\title{
Central Monitor Based On Personal Computer Using One Wireless Receiver
}

\section{(Electrocardiograph and Heartrate)}

\author{
Muhammad Nezar Abdullah Mufarid”,Bambang Guruh I, Andjar Pudji \\ Department of Electromedical Engineering Poltekkes Kemenkes, Surabaya \\ Jl. Pucang Jajar Timur No. 10, Surabaya, 60245, Indonesia \\ muhnezarabdullah@gmail.com,bgi_ps@yahoo.com, andjar.pudji@gmail.com
}

\begin{abstract}
A Central monitor is a tool in the health field that serves to monitor the patient's condition which is centralized in one monitor display centrally. In this scientific paper raised wireless systems for sending data to one monitor. In this module there are Electrocardiograph (EKG) parameters which are a parameter to detect and measure the electrical activity of the heart muscle using measurements of biopotential signals obtained from the surface of the body. From these measurements, an ECG signal will be obtained to produce a heart rate per minute (BPM). ECG signals are obtained from measurements of the electrical activity of the heart through electrodes placed on the patient's skin using the bipolar lead method. ECG signals will be processed using a microcontroller circuit as processors. Then the data will be sent to the PC using wireless $\mathrm{HC}-11$. The data received by the PC, then processed using the Delphi application which will then display ECG charts and BPM results and abnormalities indicators if the BPM is in a condition above or below normal. By comparing the module with a standard measuring instrument, the biggest error is $0.99 \%$ which is still tolerance because the tolerance limit is $\mathbf{5 \%}$
\end{abstract}

Keywords: ECG, Heartrate, HC-11, Wireless, Microcontroller

\section{INTRODUCTION}

Patient monitors function as medical equipment used to monitor patients' physiological conditions. The monitoring process is carried out in real-time so that the physiological conditions in the patient can be identified directly [1]. This patient monitor is a standard examination device, which is in the form of ECG, respiration, blood pressure or NIBP, and blood oxygen levels or blood saturation or $\mathrm{SpO}$ [2]. In observation of medical equipment, especially the Central Monitor, which is used to monitor the condition of patients in the ICU Hospital Mardi Waluyo room, the tool is still using a cable as a medium for sending data between patient monitors to the central monitor. Along with the development of current technology such as Wireless networks, applications can be utilized in the world of health. Such as the use of a wireless system in terms of monitoring patient condition data that has been connected between monitoring devices to the central monitor (PC) because it is seen in terms of installation more practical than using a cable. On the other hand, with the presence of a central monitor, nurses or doctors can monitor without having to repeatedly carry out data collection on each patient's bed but it can be done through a PC placed in the nurse's room or nurse station.
Research has been carried out with the title "Monitoring Heart Rate equipped with Temperature Sensors with Data Sending to PC via Bluetooth" [3]. In this study using the Atmega 8535 microcontroller as a data collector and displayed on a PC using Wireless. To determine the temperature of the patient using LM35 and the BPM value of the patient obtained from processing a series of BPM instrumentation that uses Finger (sensor on the finger). This tool also features an internal PC storage with patient data. But the tool is still designed to monitor one module in patients. Research and manufacture of monitoring tools have been carried out under the title "Multipoint to Point ECG Monitoring Based on ZigBee" [4]. This tool uses a central monitoring system but monitoring is more specific to ECG monitoring and will be more effective if monitoring is applied to several parameters so that it can monitor the patient's condition in more detail. Based on the results of the next search for monitoring tools with the title "Design of an Electrocardiograph Machine based on Microcontroller Atmega" [5]. In this tool the monitoring system uses cables displayed to the PC. Where you can monitor 12 ECG leads that can be accessed via a PC. Research has been carried out with the title "Central monitor based on Personal Computer Via Wireless (ECG Parameters and Heartbeat" [6]. In this tool use 2 receivers to receive data from 2 transmitters. 
Based on the results of the discussion above the author in this proposal will make a Central Monitor based on a Personal Computer (PC) Via Wireless with 1 Receiver (Electrocardiograph and Heartbeat) which is equipped with an external alarm. With the hope that monitoring can be done through a wireless system or without using cable media as data transmission.

\section{MATERIALS AND METHODS}

\section{A. Experimental Setup}

In this research, there are 2 tools which will send digital output data of ECG signals using the HC-11 wireless module, then the data is received with 1 module receiver and processed by a PC by displaying the signal graph and BPM (Beat Per Minute).

\section{1) Materials and tools}

This study uses a clamp electrode (Fukuda Denshi) as a human bioelectric signal tapper. A circuit of instrumentations designed with operational amplifier TL084 OP-AMP. Arduino Nano microcontroller as ECG signal data processor and HC-11 wireless module as data transmission. ECG Phantom is used for calibrating the module.

\section{2) Experiment}

after the design was completed then the frequency response of this device was tested using a function generator according to the specification of the ECG signal. In the calibration stage, the ECG was tested using an ECG Phantom with all range (30, 60, 120,180 , and 240 BPM). Each setting, the output of the ECG was calculated to validate the result of this study.

\section{B. The Diagram Block}

The following is a block diagram of a system module consisting of block module diagram 1 (Transmitter/ sender 1), block module diagram 2 (Transmitter/ sender 2) and receiver/ receiver block:

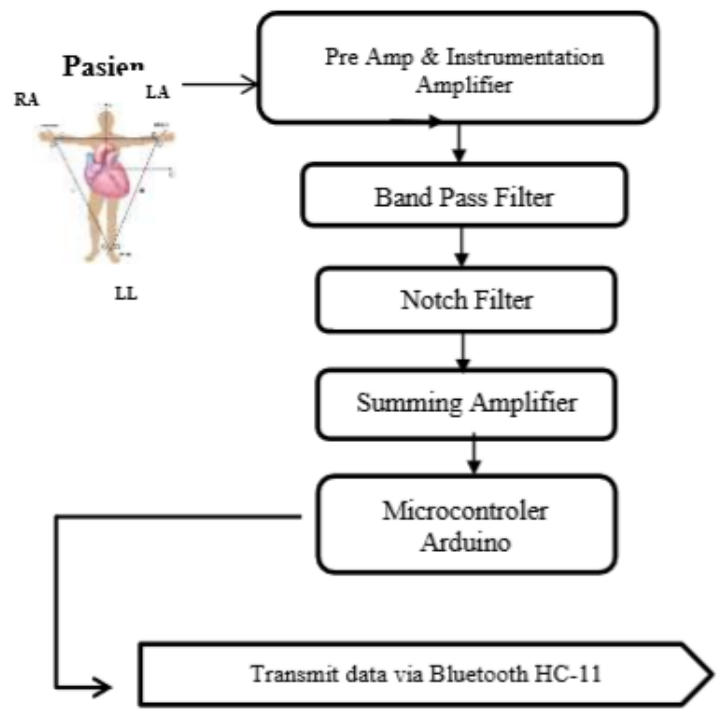

Fig. 1. Block Diagram of Modul 1 (Blok Transmitter/ sender 1)

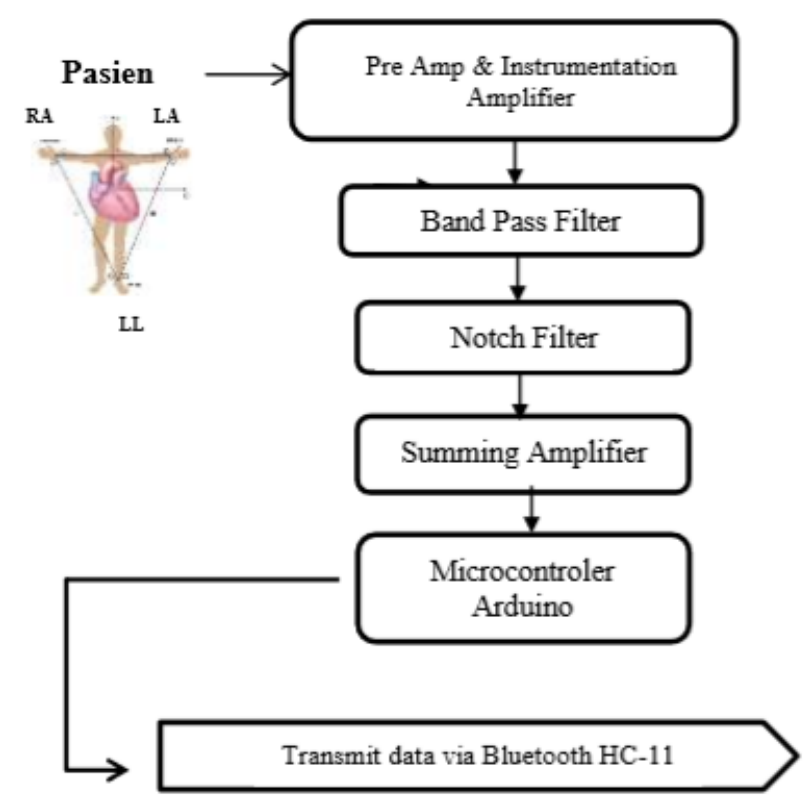

Fig. 2. Block Diagram of Modul 2 (Block Transmitter/sender 2)

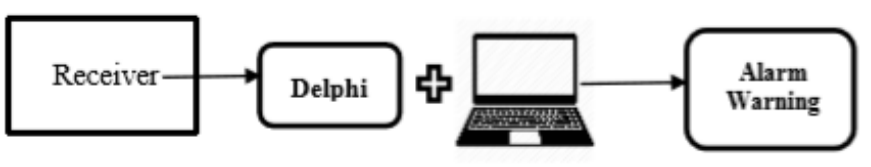

Fig. 3. Block of Receiver

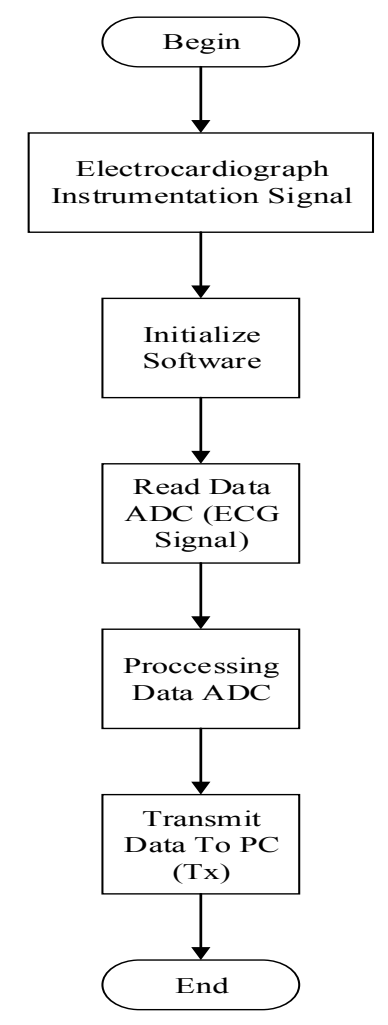


Fig. 4. Flow Chart of ECG (Electrocardiograph) Transmitter

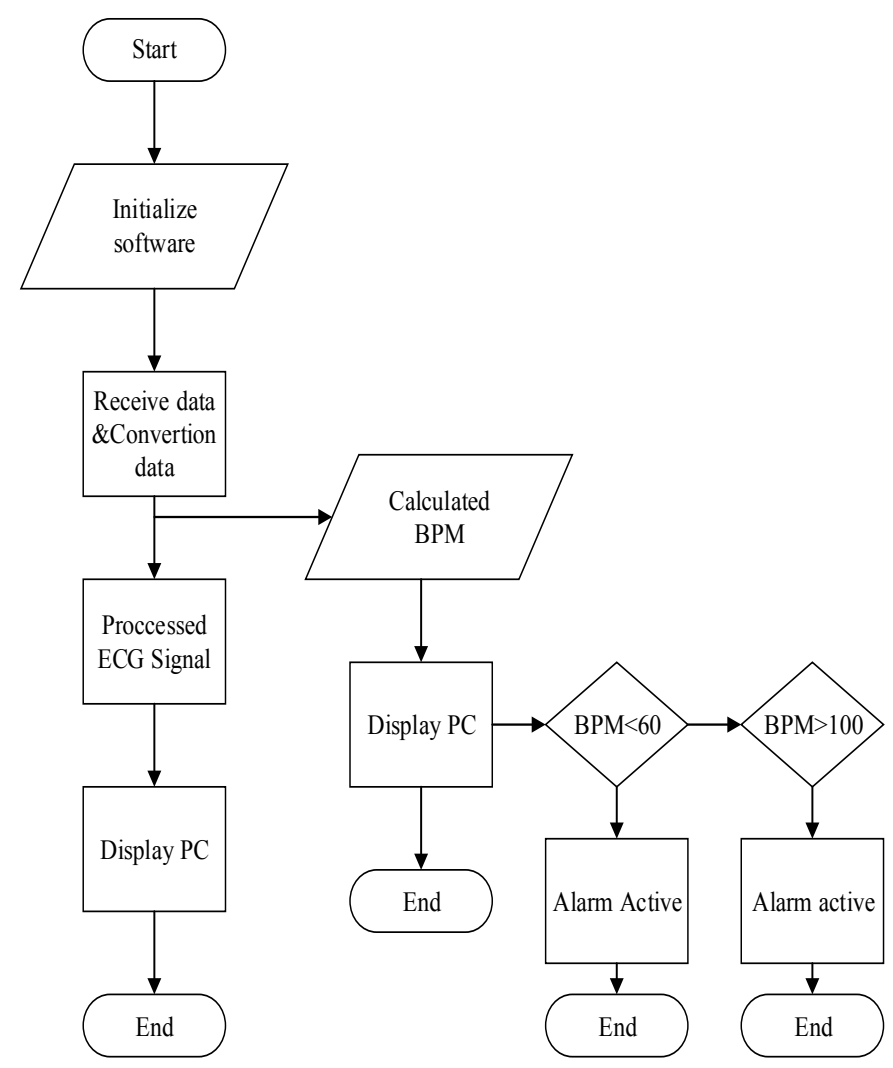

Fig. 5. Flow Chart of ECG (Electrocardiograph) receiver

\section{The Flowchart}

The Arduino program was built based on the flowchart as shown in Fig. 4. After the initialization of the Arduino, the program asks the wireless module whether the connection is active or not. If the Bluetooth is active, then the data was ready to send to the computer. On the computer, the data that has been sent will be processed using the Delphi application and will later display a graph of the ECG signal and the calculation of the BPM results

\section{The Analog Circuit}

The important part of this development is the analog circuit which describes in Fig. 6 (instrumentation amplifier), Fig. 7 (High pass filter), Fig. 8 (low pass filter), Fig 9 (notch filter) and Fig. 10 (summing amplifier). The circuit is used to process the ECG signal. Hence it will ready for digital processing using Arduino.

\section{1) Preamplifier}

An instrument amplifier is a closed-loop amplifier with differential input that can be adjusted to gain. The instrument amplifier circuit is composed of differential amplifier circuits and buffer amplifiers. To adjust the desired gain is set by changing the value of $\mathrm{Rg}$ (Resistor gain).

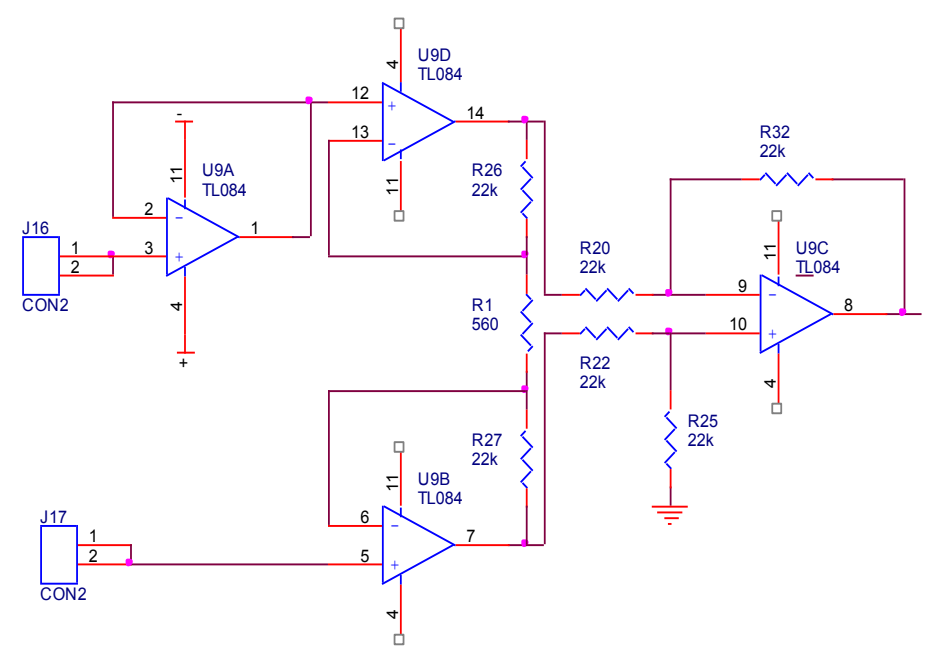

Fig. 6. Instrumentation amplifier

\section{2) High Pass Filter}

High pass filters are types of filters that pass high frequencies and suppress frequency amplitude lower than the cut-off frequency. The simplest high pass filter consists of a capacitor that is connected parallel to the resistor. The high pass filter circuit output enters the low pass filter on circuit HPF has frequency cut off $0.049 \mathrm{~Hz}$

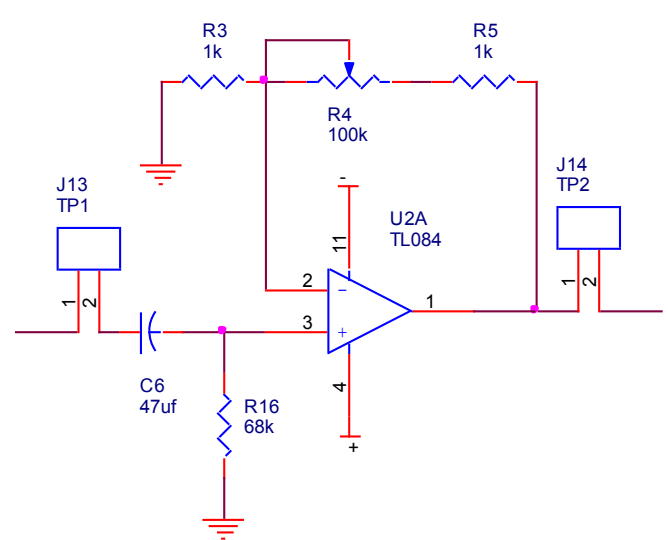

Fig. 7. High Pass Filter

\section{3) Low Pass Filter}

Low Pass Filter (LPF) is a filter used to pass electrical signals with a frequency lower than the cut-off frequency and will weaken the signal higher than the cut-off frequency. So, on a low pass filter, a signal with a frequency above the cut-off frequency will not be missed at all $(\mathrm{Vo}=0$ volts $)$. 


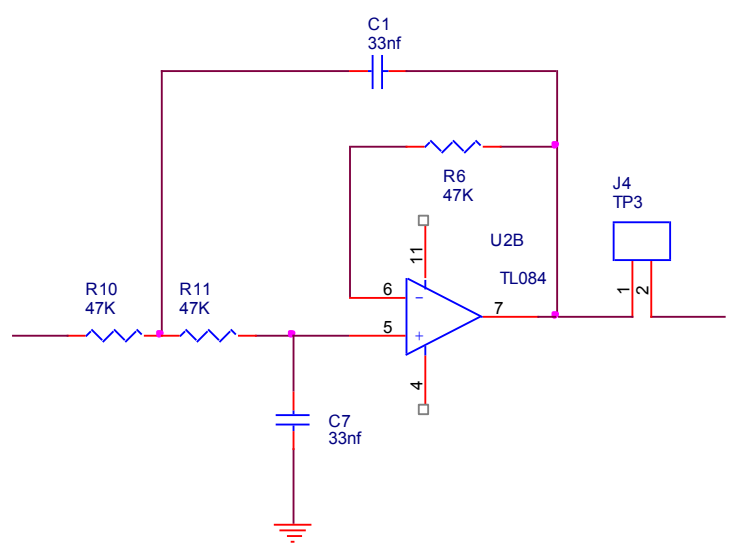

Fig. 8. Low Pass Filter

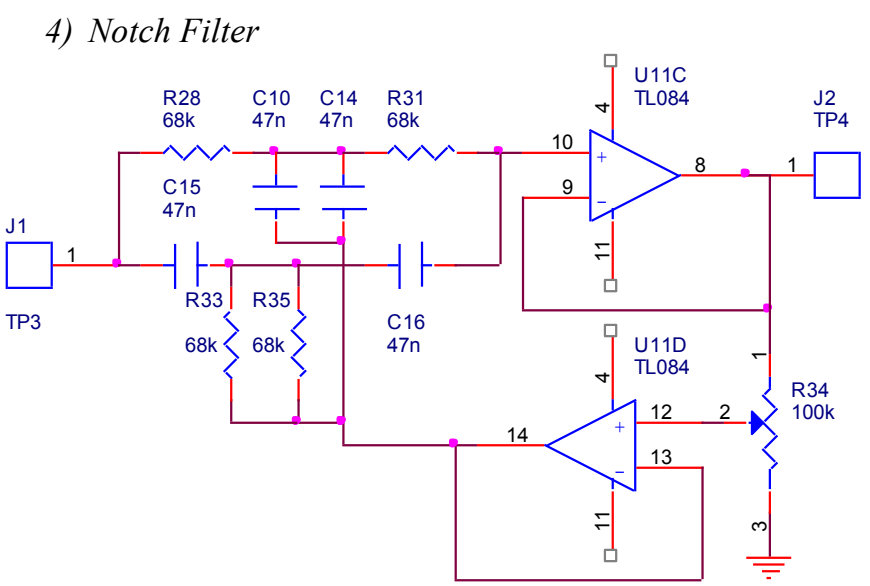

Fig. 9. Notch Filter

The filter circuit works well where the signal results are cleaner. The amplitude of the filter north circuit on TP4 (J8) is $1.32 \mathrm{~V}$ with a cut-off frequency of $49.82 \mathrm{~Hz}$.

\section{5) Summing Amplifier}

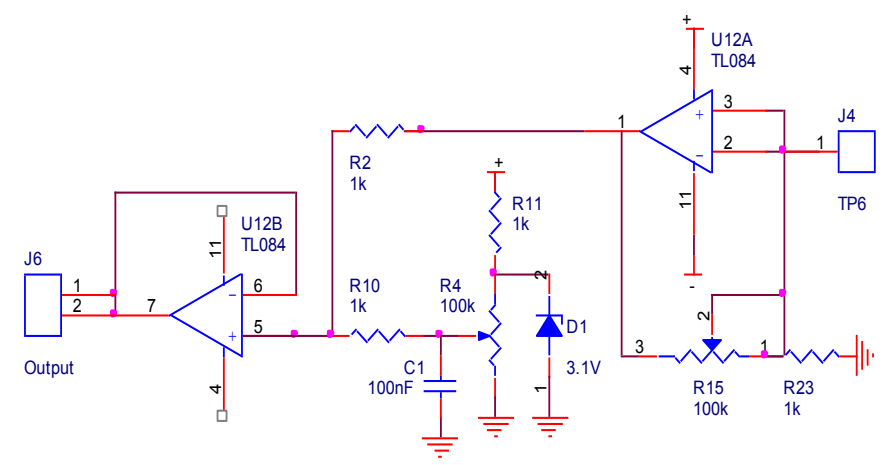

Fig. 10. Summing Amplifier

ECG signal is an AC signal so that the ECG signal voltage can be sampled in full by the internal ADC of the microcontroller then an adder circuit is needed. This circuit serves to raise the voltage level on the ECG signal so that a negative portion of the ECG signal rises to a positive voltage total.

\section{6) Wireless Module Transmitter}

The transmitter block connecting the wireless HC-11 to the minimum system (Arduino Nano) contained in each module (in module 1 and module 2). The transmitter block functions to send data that has been processed by the microcontroller to the receiver block. The following is an image of the transmitter circuit

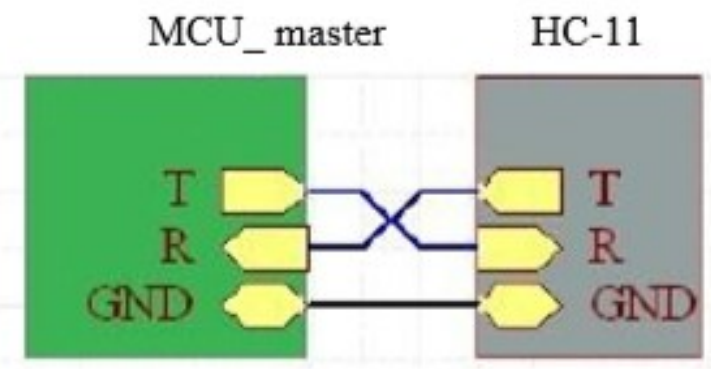

Fig. 11. Block Transmitter Circuit

\section{7) Wireless Module Receiver}

The receiver block connecting between the wireless HC-11, the PL-2303 module, and the USB connected to the PC. The receiver block functions to receive data sent from the transmitter block which is then processed on a PC using the Delphi application. The following is a schematic image of the receiver circuit:

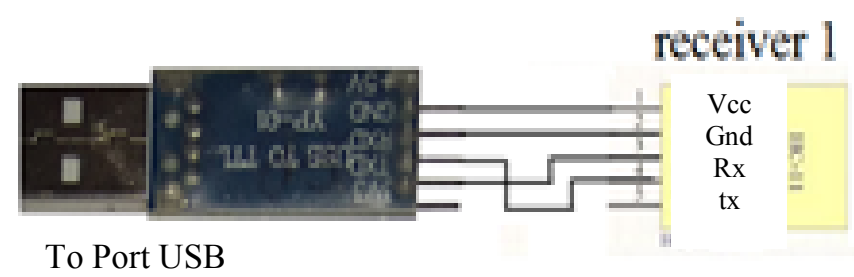

Fig. 12. Block Receiver Circuit

\section{RESULTS}

The ECG monitor has been tested by an ECG phantom (BIOTEK, ECG-plus) and ECG from the human body. In this case, the workings of the device, namely the human bioelectric signal tapped using electrodes and then amplified and filtered through a series of ECG machines, which are then processed using Arduino Nano microcontroller processors, then the output signal is sent using a wireless transmitter. 


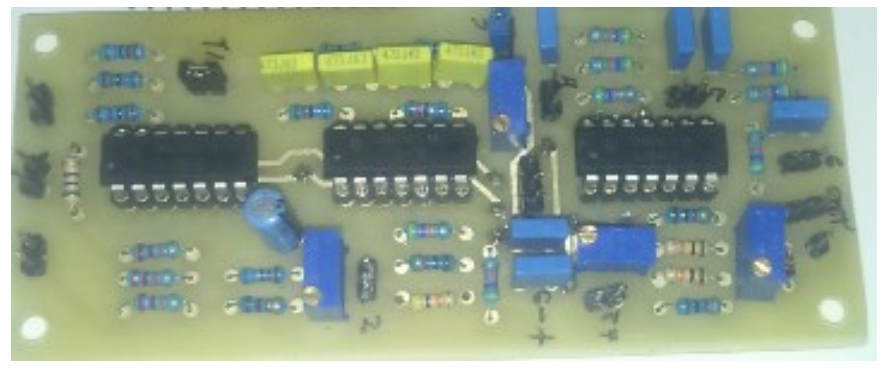

Fig. 13. Circuit ECG Design

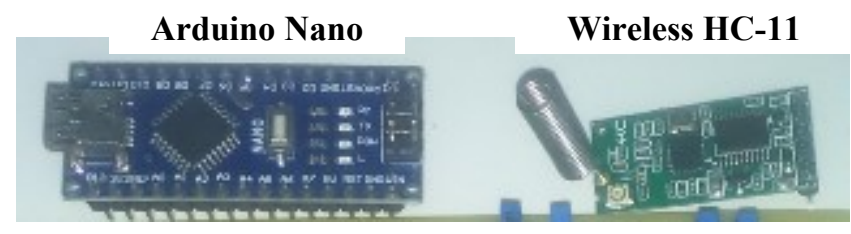

Fig. 14. Digital part of Central Monitor

\section{A. The Central Monitor ECG Design}

The image of the component part of the central monitor is shown in Fig 13 and Fig 14. In the analog section, there is the IC TL084 as an Operational Amplifier. In the digital part there is an Arduino Nano microcontroller that functions as an ECG data processor, the wireless module functions to communicate serial data between modules and computers. In this study there are 2 tools in which module 1 sends data, then the graph of Patient Signal 1 will appear on the computer. If module 2 sends data, then the graph of Patient Signal 2 will appear on the computer

\section{B. The Listing Program for Arduino}

In this discussion is about the program on Arduino to send data to a computer

\section{Listing program 1. Program to send the ECG data to a computer}

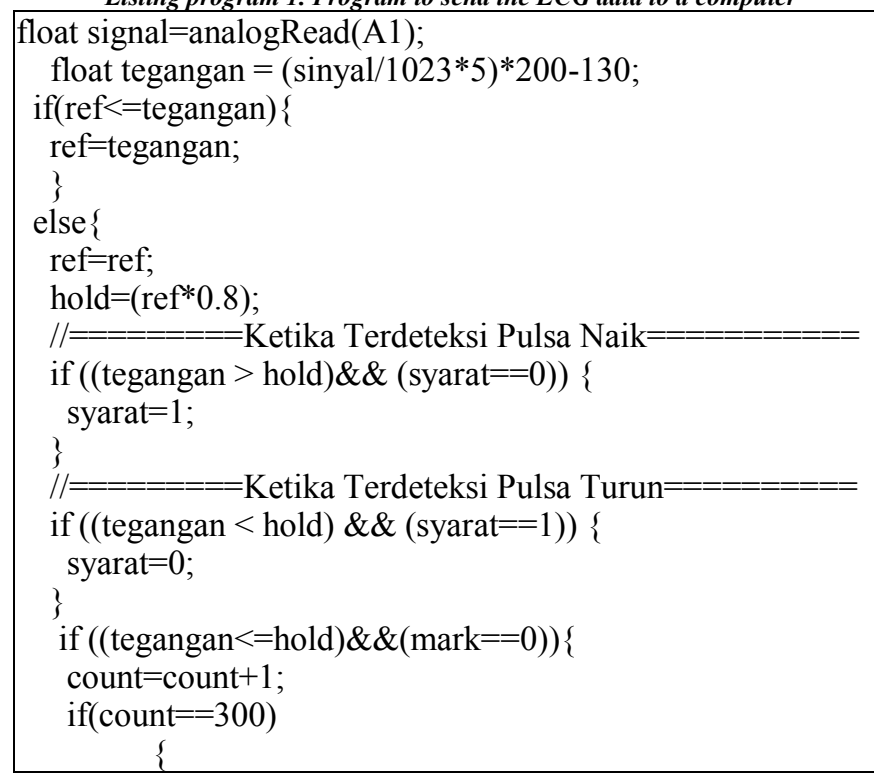

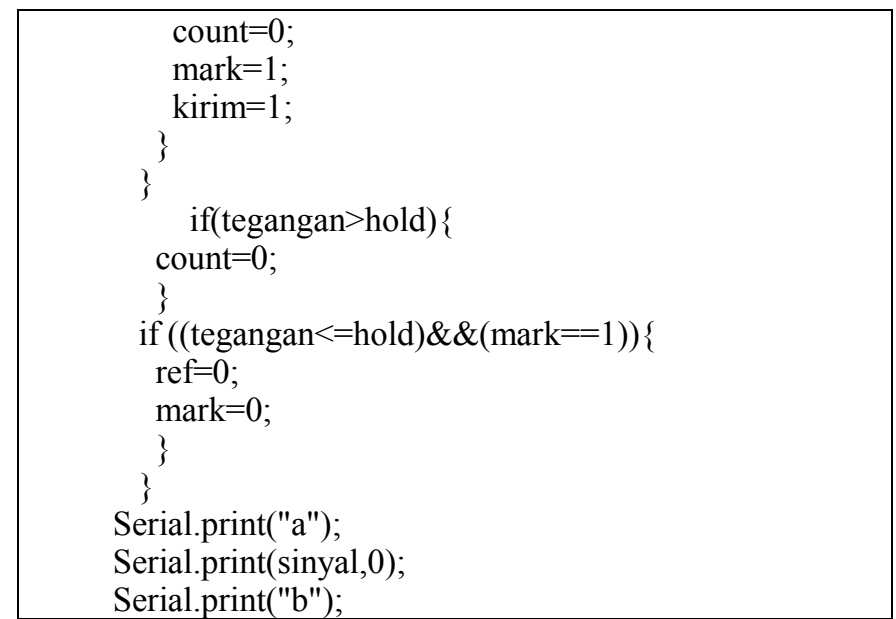

\section{The Listing Program for Delphi}

In the Delphi program, there are 2 data processing programs, namely programs to display ECG Signals and programs to display BPM

In program listing 2, it is a program to display ECG signals and BPM calculations obtained from signals that pass through the reference voltage

Listing Program 2. Program to display the ECG signal procedure TForm1.dataEKG1(Sender: TObject; const Str: String);

Var

E,dataADC:Integer;

teganganekg1:double;

begin

Val(Str,dataADC,E);

if $\mathrm{E}<0$ then Exit;

teganganekg1:=(dataADC/1023)*3.5-1;

Chart1.Series[0].AddXY(xval,teganganekg1);

Label3.Caption:=floattostr(teganganekg1);

if Chart1.Series[0].MaxXValue $>300$ then begin

Chart1.Series[0].Clear;

xval: $=0$;

end;

$\mathrm{xval}:=\mathrm{xval}+2$;

//OLAH DATA HEART BEAT==

//------------deteksi pulsa naik di atas threshold------------

if (teganganekg1 $>$ strtofloat(Label9.Caption)) And (state $=0)$ then

$$
\begin{aligned}
& \text { begin } \\
& \text { state: }=1 \text {; }
\end{aligned}
$$

end;

//-----------deteksi pulsa turn di bawah threshold---

if (teganganekg1 $<$ strtofloat(Labe19.Caption)) And

(state $=1)$ then

begin

state $:=0$;

detak: $=\operatorname{detak}+1$; 


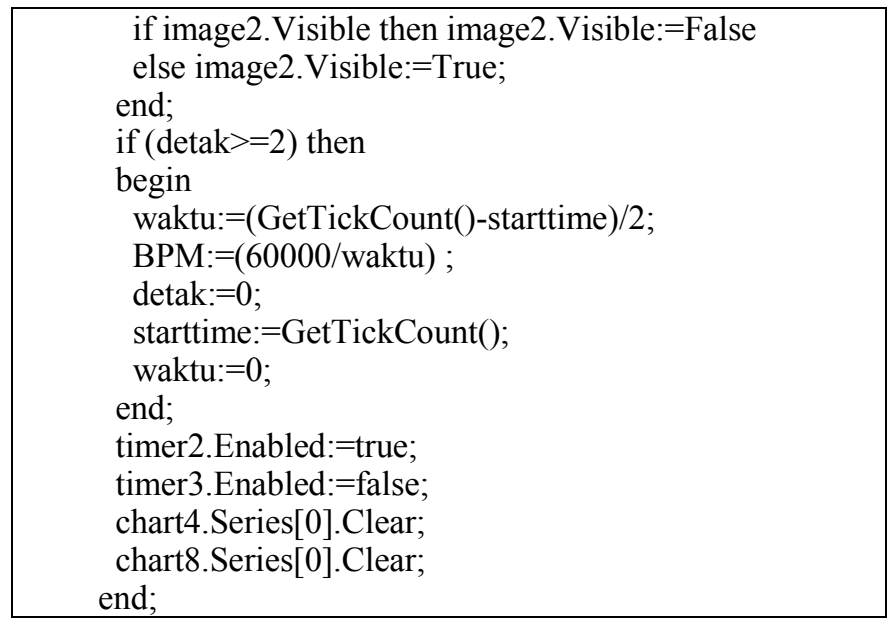

Listing Program 3. Program to show BPM and Indicator Alarm procedure TForm1.Timer2Timer(Sender: TObject); begin

$\mathrm{t}:=\mathrm{t}+1$;

Label52.Caption: $=$ floattostr(t);

if $(\mathrm{t}>=2)$ and (strtofloat(Label28.Caption) $<=0)$ then begin

$\mathrm{t}:=0$;

Label1.Caption:=formatfloat('\#0',BPM);

if(strtofloat(Label1.Caption)>100)then

begin

Label4.Font.Color:=clred;

label4.Caption:='tachicardia';

// ComPort2.WriteStr('m');

end;

if(strtofloat(Label1.Caption) $>=60$ )

(strtofloat(Label1.Caption) $<=100$ )then

begin

Label4.Font.Color: $=$ cllime;

label4.Caption:='Normal';

// ComPort2.WriteStr('n');

end;

if(strtofloat(Label1.Caption $)<60)$ then

begin

Label4.Font.Color:=clyellow;

label4.Caption:='bradicardia';

// ComPort2.WriteStr(' $m$ ');

end;

end;

if $(\mathrm{t}>=2)$ and (strtofloat(Label28.Caption) $>=1)$ then

begin

$\mathrm{t}:=0$;

detak: $=0$;

BPM: $=0$;

Label1.Caption:=formatfloat('\#0',BPM);

Comport1.WriteStr('e');

end;

end;

\section{The Error of The BPM (Beat Per Minutes) Value}

TABLE I. THE ERROR OF MEASUREMENT FOR BPM BETWEEN MODULE 1 AND CALIBRATOR.

\begin{tabular}{cc}
\hline BPM & Error $(\%)$ \\
\hline 30 & $\mathbf{0}$ \\
60 & $\mathbf{- 0 . 0 0 5 6}$ \\
120 & $\mathbf{- 0 . 0 0 8 3}$ \\
180 & $\mathbf{0 . 9 9 9 2 6}$ \\
\hline
\end{tabular}

TABLE II. THE ERROR OF MEASUREMENT FOR BPM BETWEEN MODULE 2 AND CALIBRATOR.

\begin{tabular}{cc}
\hline BPM & Error $(\%)$ \\
\hline 30 & $\mathbf{- 0 . 0 0 5 6}$ \\
60 & $\mathbf{0 . 0 0 2 7 8}$ \\
120 & $\mathbf{- 0 . 0 1 1}$ \\
180 & $\mathbf{0 . 9 9 9 2 6}$ \\
\hline
\end{tabular}

The measurement of BPM value in which the ECG signal was also compared in this study, between the module design and ECG Phantom. The result was shown in Table 1 and Table 2.

\section{DISCUSSION}

Based on the results of the discussion and the purpose of making the module it can be concluded that. The output of the amplifier instrument circuit is very small and the EKG signal is not formed, so it needs to be filtered and amplified. The output of the instrument amplifier circuit is filtered using the active high pass filter $-20 \mathrm{~dB}$ with fc $0.049 \mathrm{~Hz}$, a non-inverting gain of 101 times, low pass filter with fc $102.6665 \mathrm{~Hz}$, the filter number circuit with fc $49.8 \mathrm{~Hz}$. Making an adder circuit is used to increase the signal reference so that it can be read by the microcontroller. Using Arduino software in input and processing data in 2 parameters, namely ECG and spO2. Wireless transmitter and receiver using HC-11 module used for sending $\mathrm{ADC}$ data from the device module to $\mathrm{PC}$

\section{CONCLUSION}

Development in further research can be carried out in the following ways. Using wireless that can receive 2 or more data transmitters at the same time can be used remotely. Add other parameters according to the vital sign parameters in humans.. Using components recommended specifically for processing body signals. Make a tool with a portable system that does not require a voltage PLN / electricity $220 \mathrm{~V}$

\section{REFERENCES}

[1] D. Permana, M. W. Sanjaya, H. Aliah, F. Sains dan Teknologi, U. Islam Negeri Sunan Gunung Djati Bandung, and K. Kunci, "Desain Dan Implementasi Perancangan Elektrokardiograf (Ekg) Berbasis Bluetooth," ALHAZEN J. Phys. ISSN, vol. 2, no. 1, pp. 2407-9073, 2015. 
[2] A. Kholiq, "Akuisis Data Sinyal ECG Dan Pulse Oximetry (SPO2) Menggunakan Biomedical Measurement K1.701," Pros. SNST, pp. 7-12, 2016.

[3] R. D. A. Ikrar, "Monitoring Heart Rate , Respiration Rate di lengkapi Sensor Suhu ke Personal Komputer menggunakan Bluettoth," 2016.

[4] S. Hadiyoso and S. Aulia, "Multipoint to Point EKG Monitoring Berbasis ZigBee," Semin. Nas. Apl. Teknol. Inf. Yogyakarta, vol. 2135, pp. 19075022, 2014.

[5] B. G. Irianto, B. Budhiaji, and S. Syaifudin, "Design of Electro Cardiograph Machine Based on Atmega Microcontroller," Indones. J. Electr. Eng. Comput. Sci., vol. 2, no. 2, p. 328, 2016.

[6] A. B. Dhariyanto, "Central Monitor Berbasis Personal Computer ( Pc ) Via Wireless ( Parameter Electrocardiograph Dan Detak Jantung ),” 2018. 